Hydrol. Earth Syst. Sci., 15, 267-277, 2011

www.hydrol-earth-syst-sci.net/15/267/2011/

doi:10.5194/hess-15-267-2011

(C) Author(s) 2011. CC Attribution 3.0 License.

\title{
Modelling hourly rates of evaporation from small lakes
}

\author{
R. J. Granger and N. Hedstrom \\ National Water Research Institute, Environment Canada, Saskatoon, Canada
}

Received: 20 January 2010 - Published in Hydrol. Earth Syst. Sci. Discuss.: 4 May 2010

Revised: 13 December 2010 - Accepted: 21 December 2010 - Published: 21 January 2011

\begin{abstract}
The paper presents the results of a field study of open water evaporation carried out on three small lakes in Western and Northern Canada. In this case small lakes are defined as those for which the temperature above the water surface is governed by the upwind land surface conditions; that is, a continuous boundary layer exists over the lake, and large-scale atmospheric effects such as entrainment do not come into play. Lake evaporation was measured directly using eddy covariance equipment; profiles of wind speed, air temperature and humidity were also obtained over the water surfaces. Observations were made as well over the upwind land surface.

The major factors controlling open water evaporation were examined. The study showed that for time periods shorter than daily, the open water evaporation bears no relationship to the net radiation; the wind speed is the most significant factor governing the evaporation rates, followed by the landwater temperature contrast and the land-water vapour pressure contrast. The effect of the stability on the wind field was demonstrated; relationships were developed relating the land-water wind speed contrast to the land-water temperature contrast. The open water period can be separated into two distinct evaporative regimes: the warming period in the Spring, when the land is warmer than the water, the turbulent fluxes over water are suppressed; and the cooling period, when the water is warmer than the land, the turbulent fluxes over water are enhanced.
\end{abstract}

Relationships were developed between the hourly rates of lake evaporation and the following significant variables and parameters (wind speed, land-lake temperature and humidity contrasts, and the downwind distance from shore). The result is a relatively simple versatile model for estimating the

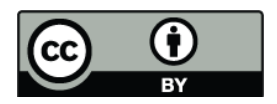

Correspondence to: R. J. Granger (raoul.granger@ec.gc.ca) hourly lake evaporation rates. The model was tested using two independent data sets. Results show that the modelled evaporation follows the observed values very well; the model follows the diurnal trends and responds to changes in environmental conditions.

\section{Introduction}

Evaporation from open water bodies is an important component of the hydrologic cycle for many watersheds. This is particularly true for boreal and northern regions; for example, in the Western Canadian Boreal region open water represents from $10 \%$ to $15 \%$ of the surface area; in portions of the Canadian Shield open water can represent as much as $20 \%$ of the surface area. Open water bodies are distributed throughout these regions; they appear in sizes ranging from small ponds to "great lakes". Many of these lakes act as storage features in complex drainage basins; they can in fact become disconnected and isolated during extended periods of drought, in which case their hydrology becomes dominated by the vertical processes of precipitation and evaporation. The correct representation of the hydrological function of these water bodies is important to the hydrological modelling of these watersheds. Also, the effect of these water bodies on the regional climate needs to be correctly incorporated into the atmospheric and climate models. Since most hydrological and meteorological models operate with time steps of the order of an hour, a reliable approach to the calculation of hourly lake evaporation is necessary to both objectives.

Even though, evaporation from open water remains largely unmeasured as a course of routine, it is still estimated with limited confidence. The major source of difficulty is the fact that the required meteorological variables are rarely measured over the water surfaces, and the thermal lag between the lake and land surfaces renders the use of land-based

Published by Copernicus Publications on behalf of the European Geosciences Union. 
measurements alone ineffective in the parameterization of open water evaporation.

Energy budget approaches, such as Morton's (1983) complementary relationship lake evaporation model have not proven to be reliable for short-term applications. An appropriate formulation of the transfer processes occurring in the advective boundary layer is required. This was demonstrated by Weisman and Brutsaert (1973), who applied analytical solutions to the advection problem over open water for the unstable case. Blanken et al. (2000), in a study of evaporation over Great Slave Lake, showed that for daily periods, open water evaporation is governed by the wind speed and the vapour gradient over the water. Granger (2000) showed that lake evaporation is largely uncoupled from (or unsynchronized with) the land surface evapotranspiration. The land surface processes closely follow the patterns of energy supply, and the partitioning of the net shortwave radiation is straightforward; the soil heat flux tends to be relatively small for most situations and the turbulent fluxes of sensible and latent heat, for the most part, behave in a similar manner. The partitioning of energy at a lake surface, on the other hand, is more complex. Because of shortwave radiation penetration, heat storage effects can be significant. The turbulent fluxes of sensible and latent heat are not necessarily in phase with the radiant energy supply, but are governed by the gradients of temperature and humidity in the boundary layer. These gradients are controlled both by water surface temperatures, which are affected by the release of stored energy and intermittent mixing of the water (Oswald and Rouse, 2004) as well as by the processes occurring over the upwind land surface (heating or cooling of the air and evapotranspiration). For these reasons, land surface data alone are insufficient to parameterize the lake evaporation; water surface data are also required.

Weisman and Brutsaert's (1973) analysis demonstrated that in an advective situation, as is the case for open water, the evaporation rate is not uniform over the lake surface, but can increase or decrease from the leading edge. Their analytical solution provided for an evaporation rate that is a function of the distance from the upwind shore. Morton (1983) also provided a method for estimating the change in evaporation as a function of distance from shore for small water bodies. Mahrer and Assouline (1993), using a meso-scale model also demonstrated the horizontal variability of open water evaporation.

Granger (2000), using lake evaporation observations made over Big Quill Lake, in Saskatchewan, showed that the analytical solutions developed by Weisman and Brutsaert (1973) can be applied when the boundary layer over the lake is unstable (temperature decreasing with height). For stable conditions, however, these analytical expressions did not work well; and an analysis of the advection under stable boundary layer conditions, such as those encountered over a lake during daytime heating of the adjacent land surface, is required. Assouline and Mahrer (1993) and Liu et al. (2009) also showed that the open water evaporation is greatly affected by the stability of the overlying air, which is governed by the land-lake temperature contrast.

There are limits to the lake size for which an approach such as that of Weisman and Brutsaert (1973) can be expected to apply. When a lake is large, meso-scale atmospheric effects such as the entrainment of higher-level air can become significant. This study is limited to small lakes; that is, those for which the boundary layer over the water surface remains intact and essentially governed by the upwind land surface conditions.

The purpose of the present study was to develop relationships between the short-term (hourly) evaporation rates from open water and those significant variables: wind speed over the lake, water surface temperature, the temperature and vapour pressure gradients over the lake, atmospheric stability and upwind fetch distance.

\section{Study sites}

Three lakes, providing a range of fetch distances from $150 \mathrm{~m}$ to $11000 \mathrm{~m}$, were chosen for the study. The largest of these is Crean Lake, located within the Prince Albert National Park in Saskatchewan. A rocky spit extending from a narrow island, near the centre of the lake, provided a stable and secure platform for the instrumentation tower, with access to nearly the full spectrum of wind directions and a range of fetch distances (distance from the upwind shore) from $3600 \mathrm{~m}$ to $11000 \mathrm{~m}$. Observations at Crean Lake were obtained for the open water seasons from 2005 to 2008.

Landing Lake, near Yellowknife, North West Territories, with the instrument tower established on a rock outcrop in the lake, provided fetch distances ranging from $150 \mathrm{~m}$ to $900 \mathrm{~m}$. Observations at Landing Lake were obtained for the period 2007 to 2008.

For the 2009 season, the northern portion of Whiteswan Lake (known as Whiteswan4), in Northern Saskatchewan was also instrumented; the instrument tower was set up on a long, narrow spit extending into the lake. This site provides fetch distances from $300 \mathrm{~m}$ to $4000 \mathrm{~m}$.

Figure 1 shows the shape and size of the study lakes, as well as the position of the instrumentation on each lake. The contour lines suggest the surrounding terrain roughness and provide an indication of the elevation of each lake. Table 1 presents the geographical locations of the lake and land towers, as well as the size characteristics of the study lakes. For each lake, the instrumentation included a direct measurement of the latent and sensible heat fluxes using the eddy covariance technique; the equipment used consisted of a Campbell Scientific CSAT three-axis sonic anemometer, coupled with a $\mathrm{KH} 2 \mathrm{O}$ krypton hygrometer. The eddy covariance instrumentation was typically deployed at a height of $3 \mathrm{~m}$ above the water surface. The incoming and reflected short-wave radiation (Kipp \& Zonen Silicon Pyranometers) and net all-wave 
Table 1. Characteristics of three study lakes.

\begin{tabular}{llllr}
\hline Lake & Observation period & Location of Flux Tower & Range of Fetch Dist. & Location of Land Tower \\
\hline Crean Lake, PANP & 2005 & $54.06353^{\circ} \mathrm{N}, 106.19170^{\circ} \mathrm{W}$ & $3600 \mathrm{~m}-11000 \mathrm{~m}$ & $53.8926^{\circ} \mathrm{N}, 106.12066^{\circ} \mathrm{W}$ \\
Crean Lake, PANP & $2006-2009$ & $54.06353^{\circ} \mathrm{N}, 106.19170^{\circ} \mathrm{W}$ & $3600 \mathrm{~m}-11000 \mathrm{~m}$ & $54.00806^{\circ} \mathrm{N}, 106.20035^{\circ} \mathrm{W}$ \\
Landing Lake, NWT & $2007-2009$ & $62.55915^{\circ} \mathrm{N}, 114.41365^{\circ} \mathrm{W}$ & $150 \mathrm{~m}-900 \mathrm{~m}$ & $62.59559^{\circ} \mathrm{N}, 114.43857^{\circ} \mathrm{W}$ \\
Whiteswan4 Lake, Sask. & 2009 & $54.17640^{\circ} \mathrm{N}, 105.1642^{\circ} \mathrm{W}$ & $300 \mathrm{~m}-4000 \mathrm{~m}$ & $53.98711^{\circ} \mathrm{N}, 105.11773^{\circ} \mathrm{W}$ \\
\hline
\end{tabular}
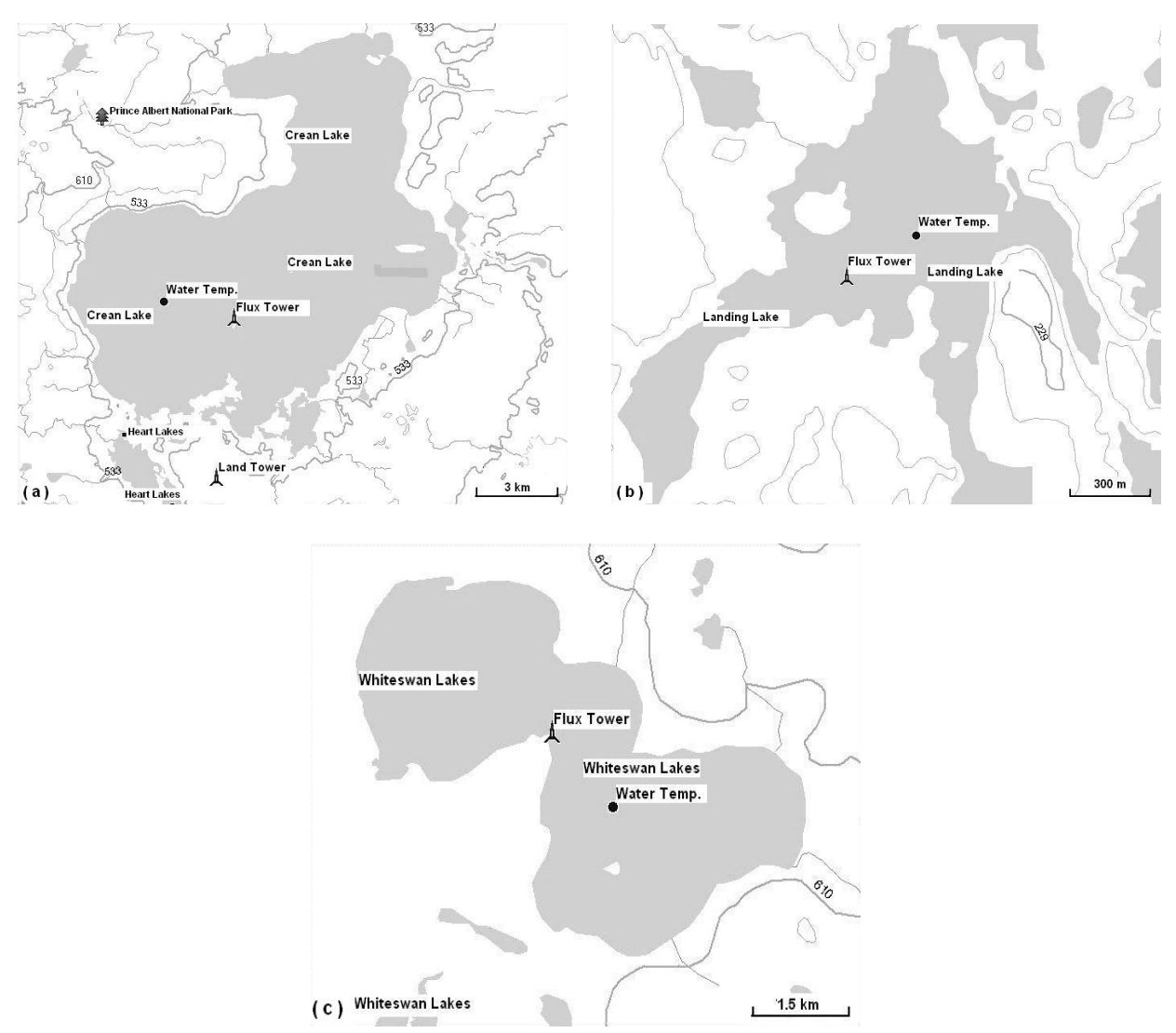

Fig. 1. Instrumented Lakes showing location of instrument towers; (a) Crean Lake, Prince Albert National Park, Saskatchewan; (b) Landing Lake, North West Territory; (c) Whiteswan4 Lake, Saskatchewan.

radiation (REBS Q7 radiometers) were also measured. Profiles were obtained consisting of at least two levels of air temperature and humidity (calibrated and shielded HMP45 Vaisala RH and Temperature Probes) and wind speed (calibrated NRG cup anemometers). The lower levels of the temperature/RH and wind speed sensors were established at 1.5 and $2.0 \mathrm{~m}$, respectively; the height of the second level varied, depending on the type and height of tower in use. Wind direction and the infrared water surface temperature were also measured. For each lake a water temperature profile was established near the centre of the lake. Near each lake, an instrumented tower over the land surface provided the shortwave and net all-wave radiation fluxes as well as the wind speed, wind direction, air temperature and humidity. All data were recorded on half-hour intervals.

\subsection{Data control and analysis}

The data from all sites were systematically examined for quality and completeness. Particular attention was paid to the turbulent fluxes of latent and sensible heat; the following corrections were applied to the eddy covariance measurements: coordinate rotation (Kaimal and Finnigan, 1994) the WPL adjustment (Webb et al., 1980), adjustments for sonic path length, high frequency attenuation and sensor separation (Massman, 2000; Horst, 1997) and oxygen extinction for the krypton hygrometer.

The Thorthwaite and Holzman (1939) aerodynamic equations with stability corrections were applied to the profile measurements of wind speed, air temperature and vapour pressure, providing a second, independent determination of 
the latent and sensible heat fluxes. Granger (1991) showed that these equations provide reliable estimates of latent heat flux rates. These profile calculations allowed for additional quality control and gap-filling of the direct eddy flux measurements of evaporation. Gaps in the eddy covariance flux measurements, generally caused by rain events, represented from 9 to $13 \%$ of the observations at the various sites. The gap-filling thus allowed for the determination of seasonal totals; however, only the valid eddy covariance measurements were used in the model development.

Wind speed, air temperature and humidity data from the land tower provided the contrast between the land and lake surfaces.

\subsection{Controls on evaporation}

Most evaporation models are based on the representation and parameterization of one or more of the conditions required for evaporation to occur; these are: the supply of water at the surface; the supply of energy required for the phase change from liquid to vapour; and the transport mechanism which carries the water vapour away from the surface.

Understanding how these conditions are controlled in various situations is necessary for the correct parameterization of the evaporation process. For land surface evaporation, most models in fact represent all three conditions; the moisture availability is parameterized using soil moisture or a "stomatal resistance", the net radiation absorbed at the surface is the available energy, and a vapour transfer function based on wind speed is applied. For lakes, however, the supply of water at the surface is non-varying, and as such is not a useful parameter. Also, since the short-wave radiation penetrates the lake surface, the radiant energy is absorbed at depth and is not immediately available for the phase change at the surface; there can be very little relationship between the available energy and the turbulent exchanges of heat and water vapour over the lake surface for sub-daily time periods.

This leaves essentially the vapour transport mechanism to work with in the development of a model for the hourly estimate of open water evaporation. The transport mechanism is governed by the vapour pressure gradient above the surface, and the efficiency of the exchange is controlled by the wind speed and the atmospheric stability; stability, in turn, is a function of the temperature gradient above the surface.

However, the air temperature and humidity are rarely measured above the lake water surface. Meteorological stations are invariably placed on land. For small lakes, however, since the boundary layer generally remains intact and undisturbed by large-scale atmospheric effects, the conditions over the lake will be governed by the upwind land surface conditions. To test this hypothesis, the land-lake temperature contrast (air temperature over land minus water surface temperature) was compared to the temperature gradient over the lake. At Crean Lake and Landing Lake, these were of the same sign for $95 \%$ and $92 \%$ of the hourly periods, respectively. These values are quite large when one considers the thermal lag between the land and lake surfaces. They do suggest that the land-lake temperature contrast can be used as a proxy for the temperature gradient over water in the determination of the atmospheric stability conditions over the lake. This is consistent with Badrinath et al. (2004) who suggested that for small water bodies the land-lake temperature contrast exercises control over the turbulent fluxes over the water.

In order to determine which are the most significant variables affecting lake evaporation, the relationships between the hourly evaporation rates over water and several meteorological variables were examined. Figure 2 presents these relationships for (a) net radiation at the lake surface, (b) wind speed over the lake, (c) land-lake temperature contrast, and (d) lake-land vapour pressure contrast. The figure shows the results for the 2006 Crean Lake data only; the relationships for the other sites and other field seasons are similar. Figure 2a shows that, unlike evaporation from land surfaces, the hourly open water evaporation rate bears little or no relationship to the net radiation. The hourly open water evaporation rate is most strongly affected by the wind speed over the lake. Although the vapour transfer function is defined by the vapour pressure gradient, the land-lake temperature gradient actually shows a stronger relationship: this is likely due to the strong effect of atmospheric stability on the evaporation rates.

Since many of the current evaporation models, such as that of Morton (1983) use net radiation as one of the controlling parameters, it is useful to demonstrate how the relationship between evaporation and net radiation is affected by the time scale and by water depth. Crean Lake is a relatively deep lake; the portion of the Lake that was studied is typically 21 to $25 \mathrm{~m}$ deep. Landing Lake is a relatively shallow lake, with an average depth of 3 to $4 \mathrm{~m}$. For each lake the correlation coefficients were determined for the relationship between evaporation and net radiation for hourly, daily, weekly and monthly periods. For Crean Lake, the relationship showed $R^{2}$ values of $0.009,0.003,0.004$ and 0.023 , respectively. Thus, for a deep lake, even at the monthly time scale, one sees very little relationship between evaporation and net radiation. This suggests that modelling approaches such as the Priestley and Taylor (1972) technique, which uses only net radiation and a correction factor, will be of little use in estimating evaporation from open water bodies such as Crean Lake. For the shallower Landing Lake, the respective $R^{2}$ values were $0.212,0.354,0.731$ and 0.927 . Thus, for a shallow lake, the energy input is reflected more quickly in the surface temperature, and there may be a definable relationship between evaporation and net radiation only for periods greater than weekly; but for hourly periods, the relationship remains weak.

The open water evaporation is most closely controlled by the wind speed over the lake (Fig. 2b). Although wind speed is a standard, routinely observed parameter over land surfaces, it is not commonly measured over lake surfaces. The 


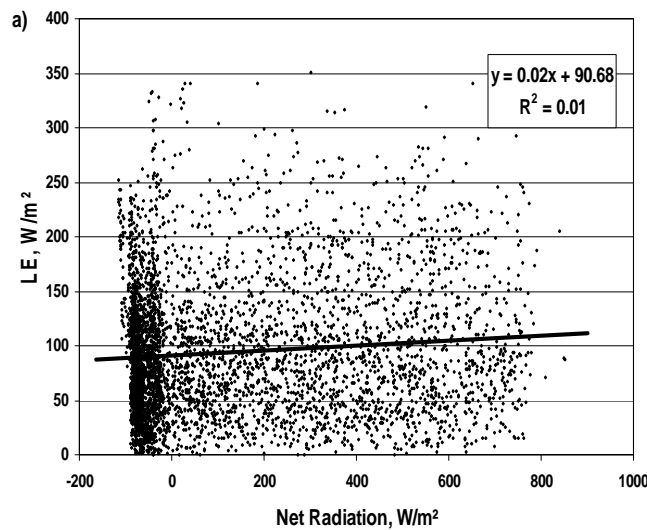

b)
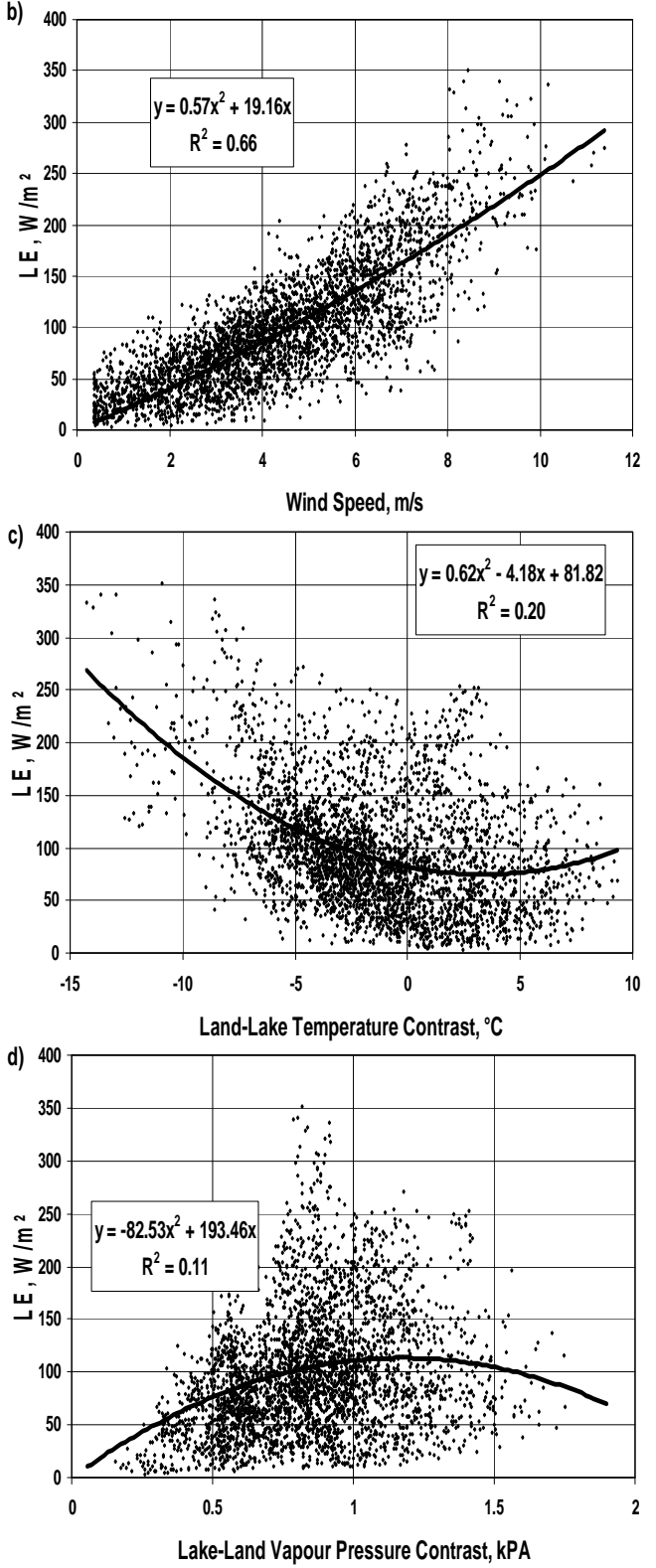

Fig. 2. The observed relationship between the hourly evaporation over Crean Lake, 2006, and (a) net radiation, (b) wind speed, (c) land-lake temperature contrast, and (d) lake-land vapour pressure contrast.

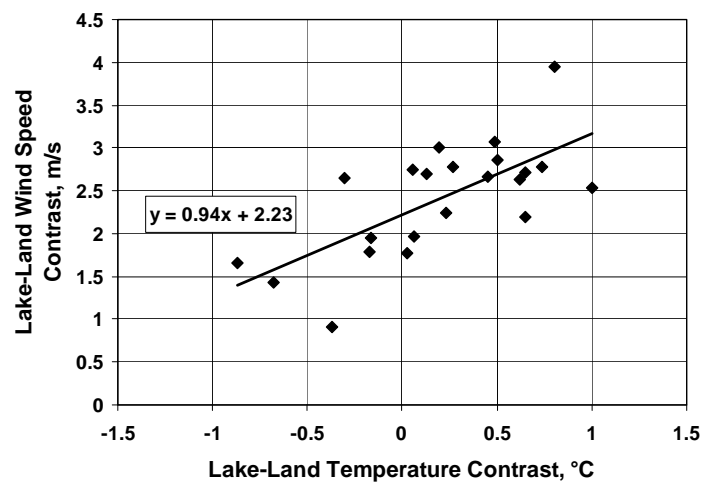

Fig. 3. The observed relationship between the 5-day average lakeland wind speed contrast and the lake-land temperature contrast, for Crean Lake, 2006.

water surface is smoother than the land surface, and so the wind speeds will tend to be greater over the water surfaces. To examine how the wind speed over a lake may be affected by atmospheric stability, the lake-land wind speed contrast was compared to the lake-land temperature contrast for 5-day periods at Crean Lake in 2006. These are presented in Fig. 3. The figure shows that for neutral conditions, the wind speed over Crean Lake tends, on average, to be $2.23 \mathrm{~m} / \mathrm{s}$ greater than the wind speed over land. Figure 3 also shows that the wind speed over water is affected by the atmospheric stability over the lake; the wind speed contrast increases in unstable situations (lake-land temperature $>0$ ). This wind increase over water was also documented by Derecki (1981) who reported monthly wind ratios $\left(U_{\text {lake }} / U_{\text {land }}\right)$ for Lake Superior. His data showed the smallest ratio for the months of April to June, the warming portion of the season being characterised by stable conditions; the largest ratios occurred in November and December when conditions are unstable and the contrast between the land and lake temperatures is greatest (cf. Figs. 4 and 5, below). However, this relationship is also likely affected by the distance from the upwind shore. To test this, the data for both lakes and for all seasons were separated into stable and unstable cases, and sorted according to the upwind fetch distance; the following relationships were developed to relate the wind speed over the lake to that over land:

$U_{\text {lake }}=U_{\text {land }} \times\left(b+c \times\left(T_{\text {land }}-T_{\text {lake }}\right)\right)$

$T_{\text {land }}$ is the air temperature over the adjacent land surface and $T_{\text {lake }}$ is the surface temperature of the water. The coefficients, $b$ and $c$, are related to the fetch distance, $X(\mathrm{~m})$ :

For Stable conditions:

$b=1.0+0.0001247 \times X$

$c=-0.0125-4.87 \times 10^{-6} \times X$

For Unstable conditions:

$b=1.0+0.0001247 \times X$

$c=-0.0125-2.3 \times 10^{-5} \times X$ 


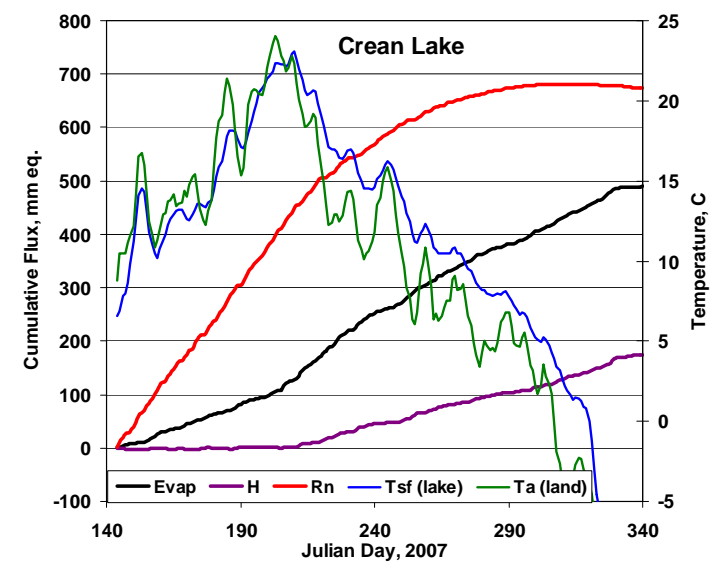

Fig. 4. The cumulative evaporation, sensible heat and net radiation for Crean Lake, 2007; showing 5-day average water surface temperature and air temperature over land.

Equations (1)-(3) can be used to estimate the wind speed over small lakes when no measurements are available.

The effect of the land-lake temperature contrast, or atmospheric stability, can also be demonstrated by examining the seasonal trends. Figure 4 shows the cumulative seasonal evaporation, net radiation and turbulent heat exchange rates as well as the temperature contrast between the lake surface and adjacent land surface at Crean Lake for the 2007 open water period. The energy terms are expressed in mm equivalent of evaporation. For the sake of clarity, the temperature values are five-day running averages. The figure shows that for the warming period, the land temperature is greater than the lake water temperature, resulting in stable conditions over the lake; whereas for the cooling period the inverse is true. The trends shown in Fig. 4 are similar to those for the other years. The figure shows that the lake evaporation is strongly affected by the thermal contrast between the lake and the adjacent land surface. In the Spring, the land surface warms more rapidly than the water surface does; this results in a predominantly stable boundary layer over the lake. In stable conditions, turbulence is suppressed, and so are the exchanges of water vapour and heat. Figure 4 shows that, although evaporation occurs during this period, there is very little turbulent heat exchange between the lake and the atmosphere. At Crean Lake, for the three study years, the average evaporation rate during the warming period was $1.85 \mathrm{~mm} / \mathrm{d}$. The land surface reaches its maximum seasonal temperature generally a few days before the lake surface, and it cools more rapidly than the water does. After this point, an unstable boundary layer (temperature decreasing with height) develops over the lake: the instability enhances turbulence and the exchanges of water vapour and heat. For the three study seasons, the average evaporation rate during the cooling period was $3.05 \mathrm{~mm} / \mathrm{d}$. This pattern of temperatures was also demonstrated by Bussières and Granger (2007), who derived

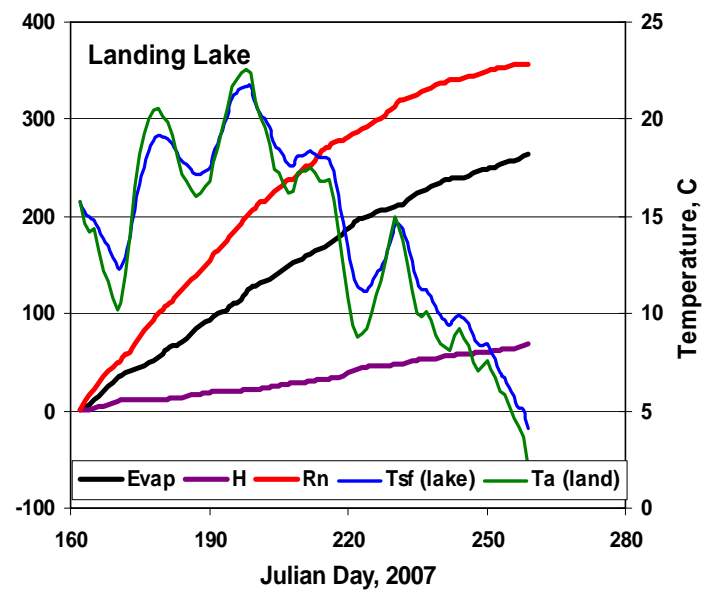

Fig. 5. The cumulative evaporation, sensible heat and net radiation for Landing Lake, 2007; showing 5-day average water surface temperature and air temperature over land.

seasonal curves of water temperature for large lakes and suggested that these will have an effect on the evaporation rates.

Figure 5 shows the cumulative seasonal evaporation, net radiation and turbulent heat exchange rates, and the temperature contrast between the lake and adjacent land surfaces at Landing Lake for the 2007 open water period. Unlike Crean Lake, the warming period at Landing Lake was not characterised by a consistent stable regime; it showed alternating periods of stable and unstable conditions. Landing Lake is located north of Great Slave Lake, such that the thermal regime over the area is significantly affected by the proximity of the large lake when southerly flows are occurring. Nonetheless, Fig. 5 does show that the turbulent fluxes are significantly modified when the regime changes from unstable to stable. For example, during the first 9-day period, shown in Fig. 5, conditions were unstable; the average evaporation rate observed was $3.86 \mathrm{~mm} / \mathrm{d}$. During the next 8day period, conditions were stable and the average evaporation rate dropped to $2.04 \mathrm{~mm} / \mathrm{d}$. During the cooling period, Landing Lake behaved the same as did Crean Lake, with a consistent unstable regime and enhanced turbulent fluxes $(3.3 \mathrm{~mm} / \mathrm{d})$. Figure 4 shows that evaporation from Crean Lake represents approximately 2.5 times more energy transfer than does the turbulent heat exchange, while Fig. 5 shows that for Landing Lake the latent heat is 3.8 times the turbulent sensible heat. This suggests that, for regions such as the boreal plain and arctic shield where open water represents a significant proportion of the surface area, correct knowledge of the lake evaporation rates are important in the regional energy balance, and indeed for the correct assessment of the meteorology of these regions. 


\subsection{Modelling evaporation rates}

The approach used in the model development was one of successive regression; that is, the most significant parameter was identified, and a relationship developed between it and the evaporation rate. The effects of the other parameters on the relationship were then incorporated in order of decreasing importance. The relative importance of the wind speed, the lake-land humidity contrast, the land-lake temperature contrast, and the net radiation on the hourly evaporation rates was shown if Fig. 2.

The Fig. 2a shows that, in fact, unlike for land surfaces, there is very little relationship between the available radiant energy and the hourly evaporation from open water; therefore, the net radiation was excluded from the analysis. The wind speed shows by far the strongest relationship with evaporation. Although the vapour transfer function is defined by the vapour pressure gradient, the temperature gradient (or land-lake temperature contrast) actually shows a stronger relationship. Hence, the model development proceeded from the relationship between wind speed and evaporation; this relationship was then modified to include in turn the effects of the land-lake temperature and lake-land humidity contrasts.

Weisman and Brutsaert (1973) showed lake evaporation includes advection and that fetch distance, or the distance from the upwind shore is also significant; therefore the effect of the fetch distance was also included in each step of the development. Most lakes are not uniform in shape, so the fetch distance was determined as a function of the wind direction.

The data from Crean Lake (2006, 2007, 2008), Landing Lake $(2007,2008)$ and from Whiteswan4 Lake (2009) were used for the model development. The data from the combined open water periods were separated into stable and unstable categories; stable cases were defined as those for which the land-based air temperature was greater than the lake surface temperature. Data for wind directions affected directly by the small island on Crean Lake and by the land point on Whiteswan4 Lake were eliminated from the analysis. The resultant data sets included approximately 10000 and 18000 values respectively for the stable and unstable categories. These were then sorted into distinct ranges of fetch distance for the analysis.

The relationship between the wind speed over the lake surface, $u$, and the evaporation rate is the basis for the model. Although Fig. 2b shows a non-linear over-all trend, for any specific set of conditions, such as a narrow range of land-lake temperature difference, the relationship is linear:

$E=a \cdot u$

where $u$ is the $2 \mathrm{~m}$ wind speed over water $[\mathrm{m} / \mathrm{s}] ; E$ is expressed as the latent energy flux $\left[\mathrm{W} / \mathrm{m}^{2}\right]$.

The coefficient, $a$, was determined as a function of the horizontal gradients (land-lake contrast) of temperature $(T)$ and
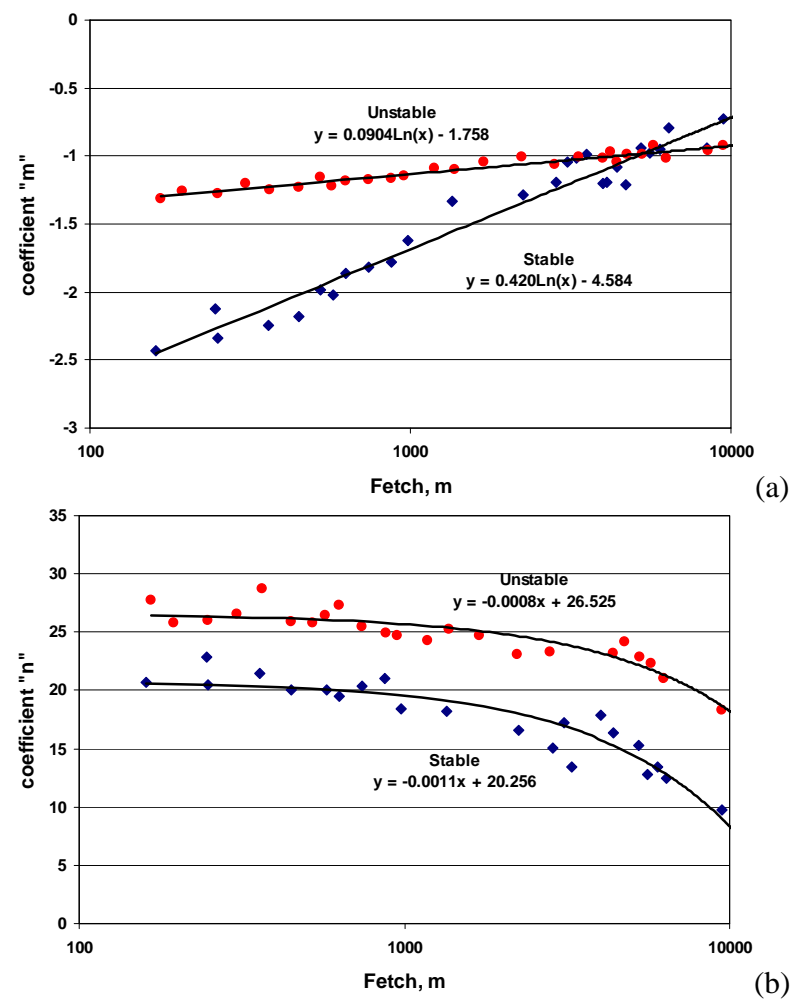

Fig. 6. The coefficients $m$ and $n$ plotted against fetch distance, for stable and unstable conditions.

(lake-land contrast) vapour pressure (e), and of the fetch distance over the open water.

$a=f(\Delta T, \Delta e, X)$

$\Delta T=T_{\text {a(land })}-T_{\text {sf(lake })},\left[{ }^{\circ} \mathrm{C}\right]$

$\Delta e=e_{\mathrm{sf}(\text { lake })}-e_{\mathrm{a}(\mathrm{land})},[\mathrm{kPa}]$

$X=$ fetch $\cdot$ over $\cdot$ water, $[m]$

The coefficient, $a$, takes the form:

$a=b+m \cdot \Delta T+n \cdot \Delta e$

Figure 6 shows the effect of fetch distance on the coefficients, $m$ and $n$, respectively; the relationships for both stable and unstable conditions are shown.

For stable conditions over the lake, i.e. $T_{\mathrm{a}(\text { land })}>T_{\mathrm{sf}(\mathrm{lake})}$ :

$$
\begin{aligned}
& b=3.395+0.0008 \cdot X \\
& m=-4.584+0.420 \cdot \ln (X) \\
& n=20.256-0.0011 \cdot X
\end{aligned}
$$

For unstable conditions over the lake, i.e. $T_{\mathrm{a}(\text { land })}<T_{\mathrm{sf}(\mathrm{lake})}$ :

$$
\begin{aligned}
& b=2.373+0.0002 \cdot X \\
& m=-1.758+0.0904 \cdot \ln (X) \\
& n=26.525-0.0008 \cdot X
\end{aligned}
$$

Equations (4-7) represent a relatively simple series of expressions which can be applied to the calculation of hourly 
evaporation rates from open water; they require as inputs, the wind speed, the surface temperature of the lake, the air temperature and humidity above the adjacent land; the wind direction and the relationship between lake fetch and wind direction are also required.

\section{Model verification and discussion}

Two data sets were available for the model verification. The first data set included the evaporation data collected on Crean Lake in 2005; this data set was not used in the model development since there was no land-based tower deployed adjacent to the lake during this first observation season. However, land-based data from the "Mixedwood" forest site, south of Waskesiu Lake, were still available, and were used in the verification calculations. Although the Mixedwood tower is not adjacent to Crean Lake, the study, for which the tower had been deployed, showed that the boreal forest is relatively uniform in that the above-canopy temperature and humidity does not vary greatly over the region (Pomeroy et al., 1997). A second data set involved the data collected over Quill Lake, Saskatchewan in 1993 (HEATMEX Experiment, unpublished).

Equations (4-7) were applied to the half-hourly observations from Crean Lake and the Mixedwood tower for the period May to September 2005. Figure 7 shows the comparison between measured and calculated half-hourly evaporation rates (expressed in energy units of $\mathrm{W} / \mathrm{m}^{2}$ ) over Crean Lake for 4 consecutive days. The figures show that the modelled evaporation follows the observed values very well; the model follows the diurnal trends and responds correctly to changes in environmental conditions (13, 14 August).

Figure 8a shows the comparison between measured and calculated evaporation rates $\left(\mathrm{W} / \mathrm{m}^{2}\right)$ for all the time periods in the 2005 data set; Fig. $8 \mathrm{~b}$ shows the comparison between the calculated and measured cumulative seasonal evaporation, expressed in mm of water. The Fig. 8a shows excellent agreement, with an $R^{2}$ value of 0.86 , for the 2250 data points. Figure $8 \mathrm{~b}$ shows that the seasonal total modelled evaporation is in very close agreement with the observed evaporation, with a total divergence between the two of $7 \mathrm{~mm}$ over 84 days.

The model (Eqs. 4-7) was also applied to the hourly observations from the Quill Lake HEATMEX Experiment in 1993. The "measured" lake evaporation values were obtained using profile data from a tower located near the centre of the lake. For the Quill Lake test, the land-based data were obtained from an instrument tower located on the western shore of the lake. In this case, all calculations were made for hourly values.

Whereas Crean and Whiteswan4 Lakes are surrounded by boreal forest and Landing Lake (NWT) is surrounded by forest and rock, Quill Lake is a classic Prairie lake, surrounded by open fields and pasture land. For this reason also,
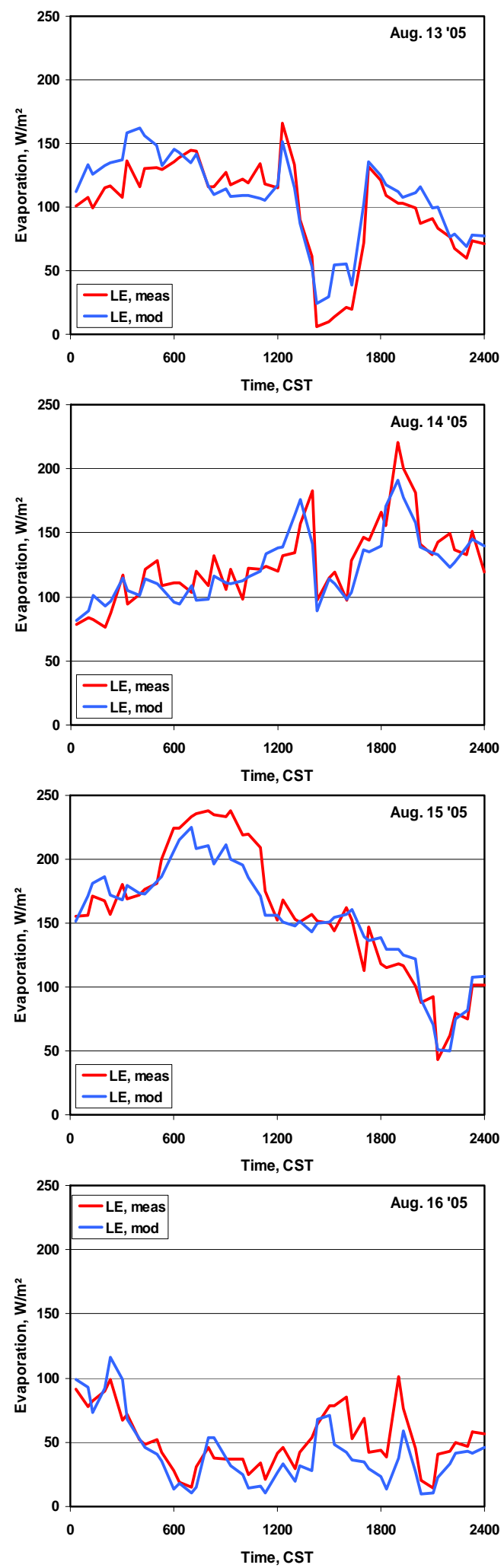

Fig. 7. The measured and calculated half-hourly evaporation rates for 4 consecutive days on Crean Lake (13-16 August 2005). 

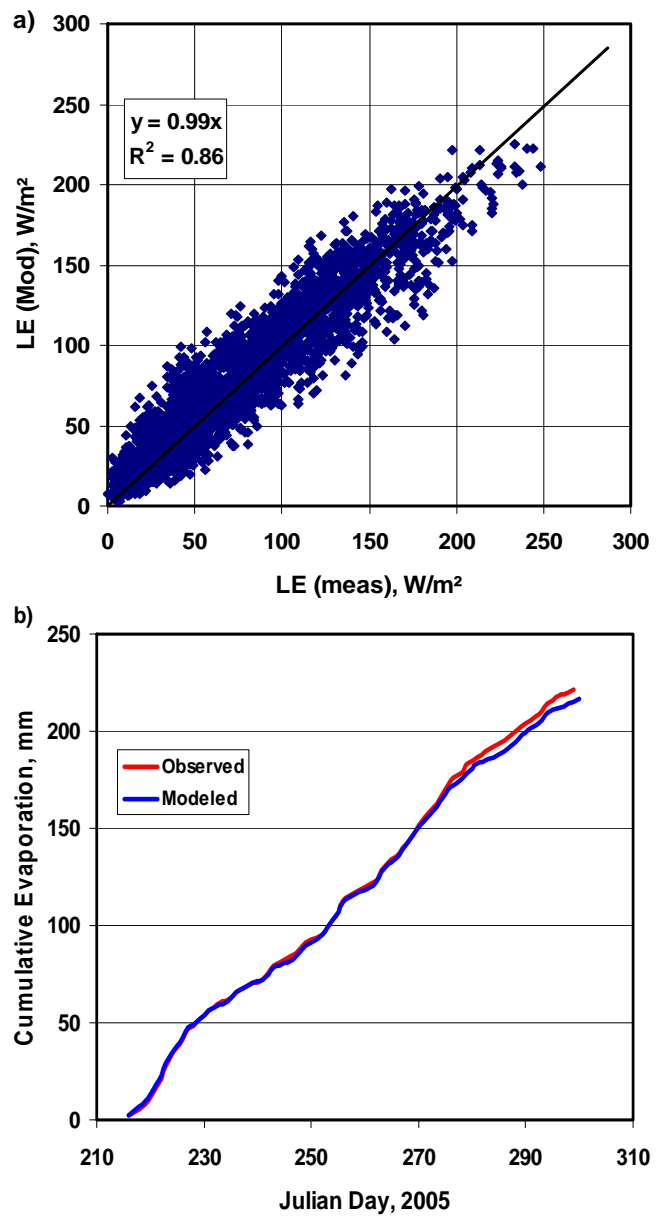

Fig. 8. Comparison between the measured and calculated evaporation from Crean Lake, 2005; (a) half-hourly evaporation rates, $\mathrm{W} / \mathrm{m}^{2}$; (b) cumulative evaporation, $\mathrm{mm}$.

Quill Lake represents a good test for the transferability of the model.

Figure 9 shows the comparison between measured and calculated hourly evaporation rates $\left(\mathrm{W} / \mathrm{m}^{2}\right)$ over Quill Lake for 4 consecutive days in 1993. The figures show that the modelled evaporation follows the "measured" values very well; it also responds correctly to the diurnal variations as well as to changes in environmental conditions (1 September).

Figure 10a shows the comparison between measured and calculated evaporation rates $\left(\mathrm{W} / \mathrm{m}^{2}\right)$ for all the time periods in the 1993 data set; Fig. 10b shows the comparison between the calculated and measured cumulative seasonal evaporation, expressed in mm of water. Although the comparison for the 1800 data points produces a smaller $R^{2}$ value $(0.75)$ than for the Crean Lake data, the agreement is still very good. The seasonal total modelled evaporation is in very close agreement with the observed evaporation, with a total divergence of $8 \mathrm{~mm}$ over 75 days.
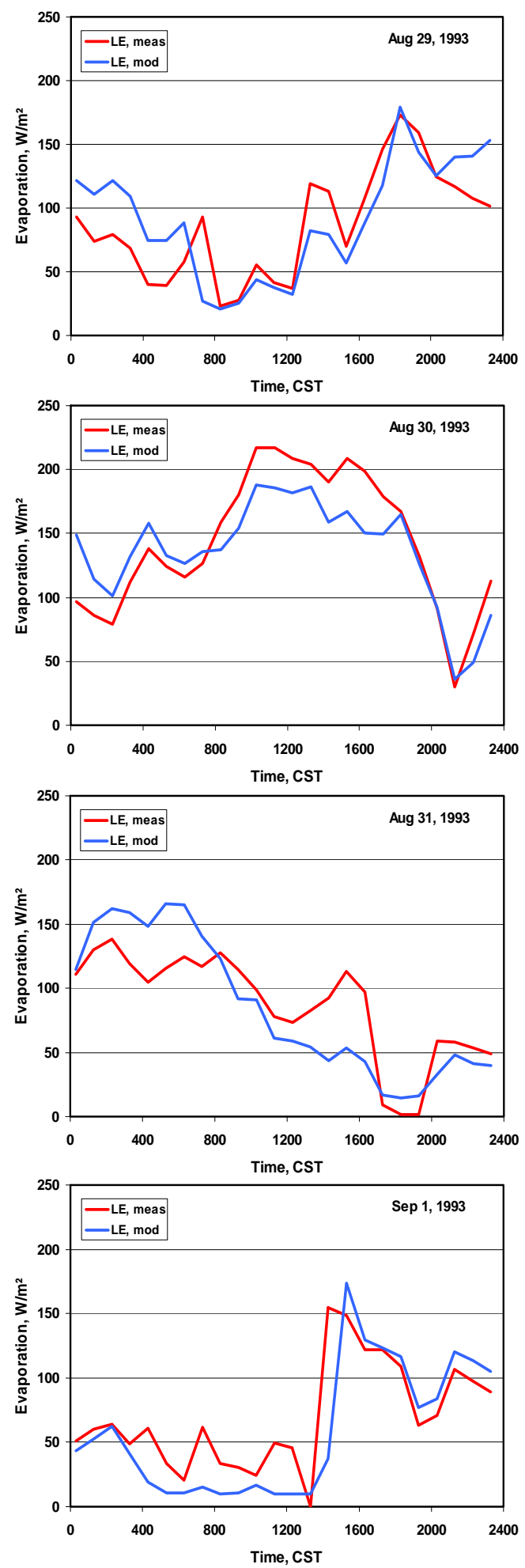

Fig. 9. The measured and calculated hourly evaporation rates for 4 consecutive days on Quill Lake (29 August-1 September 1993). 

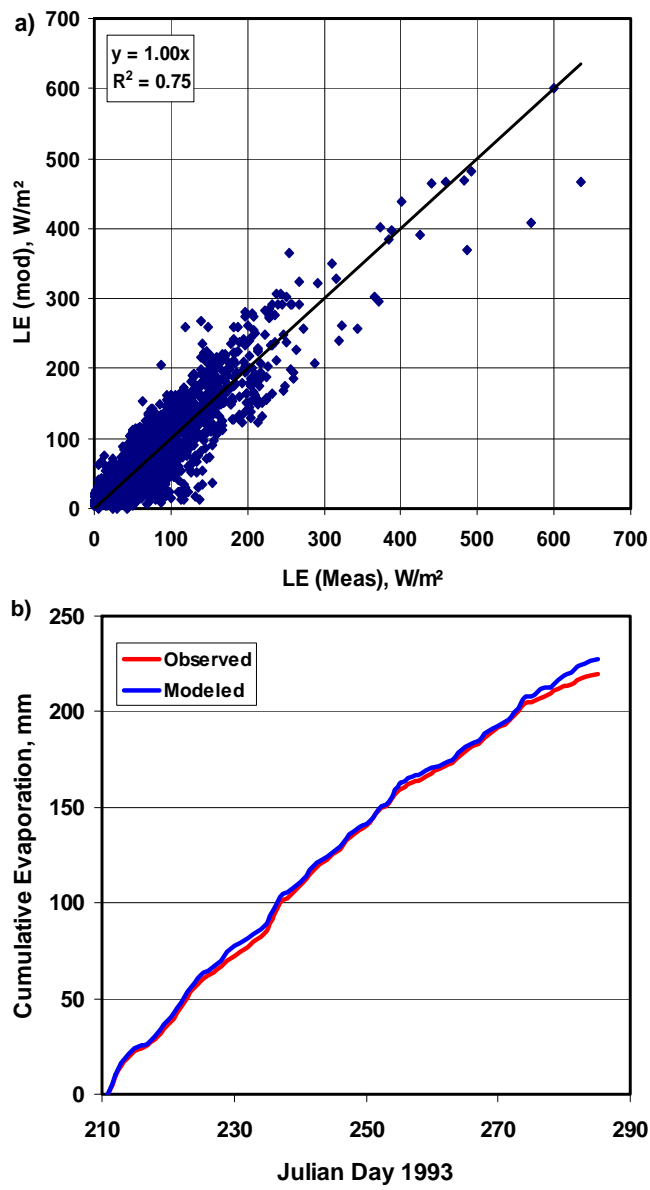

Fig. 10. Comparison between the measured and calculated evaporation from Quill Lake, 1993; (a) hourly evaporation rates, $\mathrm{W} / \mathrm{m}^{2}$; (b) cumulative evaporation, $\mathrm{mm}$.

Development of the hourly lake evapoartion model (Eqs. 4-7) has demonstrated that the lake evaporation process is governed by the wind speed over the lake (this is consistent with the findings of Blanken et al., 2000) and by the horizontal advection of air from the adjacent land surface (as has been shown by Weisman and Brutsaert, 1973 and by Liu et al., 2009).

It is intersting and useful to compare the form of the model (Eqs. 4-7) to the well-known bulk aerodynamic transfer equation:

$$
E=L C_{\mathrm{E}} u\left(e_{\mathrm{s}}-e_{\mathrm{a}}\right)
$$

Where, $L$ is the latent heat of vaporization, $C_{\mathrm{E}}$ is a bulk transfer coefficient, $u$ is the wind speed and $e_{\mathrm{s}}$ and $e_{\mathrm{a}}$ are the vapour pressures at the water surface and in the overlying air, respectively; $E$ is given in energy units $\left[\mathrm{W} / \mathrm{m}^{2}\right]$. The Bulk transfer coefficient, $C_{\mathrm{E}}$, is generally formulated from the Monin-Obukhov similarity theory with corrections for stability. The coefficient $a$ in Eq. (4) is then related to $C_{\mathrm{E}}\left(e_{\mathrm{S}}-e_{\mathrm{a}}\right)$, that is to the vertical vapour gradient and to a stability-related coefficient. Equation (5) then shows that the atmospheric stability is characterised by the land-lake temperature contrast, and the vertical vapour gradient by the land-lake vapour pressure contrast. This is not inconsistent with the analytical development of Weisman and Brutsaert who, in transforming the boundary layer equations into nondimensional form, scaled the vertical gradients of temperature and humidity with the land-lake contrasts for these variables. And, as with the Weisman and Brusaert (1973) analytical solutions, the effect of distance from the upwind shore was significant in the development of Eqs. (4-7).

The lake evaporation model presented here may be limited to small lakes; that is to say, lakes over which a consistent internal boundary layer can develop and be maintained. The data presented here suggest that this is the case at least for lakes with a fetch distance up to $10000 \mathrm{~m}$. For larger lakes, mesoscale effects, such as air mass entrainment and local circulations, may break down the internal boundary layer and the coupling between the land and lake surfaces; this would seriously reduce the applicability of this approach.

\section{Summary and conclusions}

Three successful field campaigns were carried out for measuring and modelling evaporation from small to mediumsized lakes: Crean Lake and Whiteswan Lake in the boreal plain of Saskatchewan, and Landing Lake in the Canadian Shield, north of Great Slave Lake, North West Territory. The data collected allowed for the development of a model capable of calculating the lake evaporation rates for hourly time periods. The model validation, on Crean Lake for 2005 and on Quill Lake for 1993, showed that the model does provide accurate and reliable results. The modelled evaporation follows the observed values very well; it also responds correctly to the diurnal fluctuations as well as to changes in environmental conditions.

Obtaining reliable hourly operational estimates of evaporation from individual lakes, using this method, is feasible if lake water surface temperature measurements are made available. Further study will be required to extend the limits of the model to lake fetches less than $150 \mathrm{~m}$ and exceeding $10000 \mathrm{~m}$. The application of this type of lake evaporation model within meteorological or climate models will require the development of a technique for characterizing lake size and shape.

Acknowledgements. The authors wish to express their appreciation for the support provided by the staff of the Prince Albert National Park, for the use of Park facilities and equipment. The authors also acknowledge the financial support provided by Environment Canada, and the IP3 and IPY research programs. The provision of additional data from colleagues at Environment Canada (Chris Spence, Garth van der Kamp and Randy Schmidt), is also gratefully acknowledged.

Edited by: J. Pomeroy 


\section{References}

Assouline, S. and Mahrer, Y.: Evaporation from Lake Kinneret, 1. Eddy Correlation System Measurements and Energy Budget Estimates, Water Resour. Res., 29(4), 901-910, 1993.

Badrinath, N., Yau, M. K., and Schuepp, P. H.: the effects of small water bodies on the atmospheric heat and water budgets over the Mackenzie River Basin, Hydrol. Process., 18, 913-938, 2004.

Blanken, P. D., Rouse, W. R., Culf, A. D., Spence, C., Boudreau, L. D., Jasper, J. N., Kochtubajda, B., Schertzer, W. M., Marsh, P., and Verseghy, D.: Eddy covariance measurements of evaporation from Great Slave Lake, Northwest Territories, Canada, Water Resour. Res., 36(4), 1069-1077, 2000.

Bussières, N. and Granger, R. J.: Estimation of water temperature of large lakes in cold climate regions during the period of strong coupling between water and air temperature fluctuations, J. Atmos. Ocean. Tech., 24, 285-296, doi:10.1175/JTECH1973.1, 2007.

Derecki, J. A.: Operational Estimates of Lake Superior Evaporation based on IFYGL Findings, Water Resour. Res., 17(5), 14531462, 1981.

Granger, R. J.: Evaporation from Natural Nonsaturated Surfaces, Ph.D. Thesis, Dept. of Agricultural Engineering, University of Saskatchewan, p. 141, 1991.

Granger, R. J.: Potential for the use of Remote Sensing with the Numerical analysis of Advection in the Estimate of Lake Evaporation, in: Applications of Remote Sensing in Hydrology, edited by: Pietroniro, A., Granger, R. J., and Pultz, T. J., Proceedings of the 4th International Workshop, Santa Fe, NM, 4-7 November 1998, 105-112, 2000.

Horst, T. W.: A simple formula for attenuation of eddy fluxes measured with first order response scalar sensors, Bound.-Lay. Meteorol., 94, 517-520, 1997.

Kaimal, J. C. and Finnigan, J. J.: Atmospheric Boundary Layer Flows - Their Structure and Measurement, Oxford University Press, New York, 289 pp., 1994.
Liu, H., Zhang, Y., Liu, S., Jiang, H., Sheng, L., and Williams, Q. L.: Eddy covariance measurements of surface energy budget and evaporation in a cool season over southern open water in Mississippi, J. Geophys. Res., 114, D04110, doi:10.1029/2008JD010891, 2009.

Mahrer, Y. and Assouline, S.: Evaporation from Lake Kinneret, 2. Estimation of the horizontal variability using a twodimensional numerical mesoscale model, Water Resour. Res., 29(4), 911-916, 1993.

Massman, W. J.: A simple method for estimating frequency response corrections for eddy covariance systems, Agr. Forest Meteorol., 104, 185-198, 2000.

Morton, F. I.: Operational estimates of lake evaporation, J. Hydrol., 66, 77-100, 1983.

Oswald, C. J. and Rouse, W. R.: Thermal characteristics and Energy Balance of various-size Canadian Shield Lakes in the Mackenzie River Basin, J. Hydrometeorol., 5, 129-144, 2004.

Pomeroy, J. W., Granger, R. J., Pietroniro, A., Elliott, J. E., Toth, B., and Hedstrom, N.: Hydrological pathways in the Prince Albert Model Forest, Final report to the Prince Albert Model Forest Association, Environment Canada, NHRI Contribution Series No. CS-97004, Saskatoon, Canada, 154 pp. and appendices, 1997.

Priestley, C. H. B. and Taylor, R. J.: On the assessment of Surface Heat Flux and Evaporation using large-scale Parameters, Mon. Weather Rev., 100(2), 81-92, 1972.

Thornthwaite, C. W. and Holzman, B.: The determination of evaporation from land and water surfaces, Mon. Weather Rev., 67, 4-11, 1939.

Webb, E. K., Pearman, G. I., and Leuning, R.: Correction of flux measurements for density effects due to heat and water vapour transfer, Q. J. Roy. Meteor. Soc., 106, 85-100, 1980.

Weisman, R. N. and Brutsaert, W.: Evaporation and cooling of a lake under unstable atmospheric conditions, Water Resour. Res., 9, 1242-1257, 1973. 